\title{
Die vestiging van die Kerk in Natal, die Vrystaat en Transvaal na afloop van die Groot Trek
}

\author{
JMG Storm
}

\section{Abstract}

The settlement of the Church in Natal, the Free State and Transvaal after the Great Trek.

After settling in the Orange Free State, Natal and Transvaal, the Voortrekkers established congregations in Port Natal, Pietermaritzburg, Wenen, Winburg and Potchefstroom. The House of Assembly appointed an Americal missionary, Daniél Lindley, as minister of the Voortrekkers. After the annexation by England of Natal and Orange Free State, the congregations in these areas were incorporated in the Dutch Reformed Church of the Cape Colony. The Cape Synod admitted these congregations to the Church district of Transgariep. The congregation in Transvaal was the only congregation that was left of the Voortrekkerkerk.

\section{INLEIDING}

Dit is vandag vanselfsprekend dat ons die terme 'Voortrekkers' en 'Groot Trek' gebruik om diegene aan te dui wat die Kaapkolonie in 'n groot beweging gedurende 1836-1838 verlaat het. Hierdie begrippe tref ons egter eers teen die eithde van die sestigerjare van die vorige eeu aan om die trek uit die Kaapkolonie aan te dui. Tydens die trek self is terme soos 'reizigers', 'uitgewekenen', 'landverhuizers' en veral 'Emigrante' en 'Emigrasie' baie meer aan die orde van die dag. (Van Jaarsveld 1974: 4). Hierdie Emigrante was 'n doelgerigte groep Afrikaanssprekende grensboere wat vanuit die Britse Kaapkolonie na aangrensende gebiede in die noorde en noordooste getrek het sonder die bedoeling om ooit terug te keer. Hulle het 'n bewuste afwerping van die Britse onderdaanskap ten doel gehad en wou buite die grense van die Britse gebied 'n nuwe volksplanting of nedersetting met 'n eie regering in 'n eie staat stig. Hierdie stigters van die noordelike Boererepublieke sou ook die grondlêers van die kerk in die leë binneland van Afrika word. 
Dit moet duidelik gestel word dat die vestiging en inrigting van die kerk egter nie mee gewag is tot na afloop van die Groot Trek nie. Net soos die eerste grondslae va die toekomstige Voortrekkerrepubliek reeds tydens die Trek gelê is, so is ook die noodsaaklike grondslae van 'n eie organisatoriese selfstandige kerk reeds tydens die Groot Trek gelê. Eerstens is op 21 Mei 1837 te Blesberg op inisiatief van Piet Retief, die gekose goewerneur van die Voortrekkers, eerwaarde Erasmus Smit as eerste predikant van die Voortrekkers laat orden en bevestig. Daarna het verskeie kerksake van tyd tot tyd aandag geniet.

Met betrekking tot die bevestiging van huwelike stel Retief 'n meer ordelike reëling daar, naamlik dat die gebooie van voornemende egpare van nou af drie maal in die kerk afgekondig moes word en nie soos voorheen sommer op 'n gewone vergadering nie. Ook het dit dringend noodsaaklik geword dat kerkraadslede aangewys moes word want die eerste Voortrekkerkerkraad, wat op 8 Februarie 1837 gekies is, het nooit gefunksioneer nie. Om hulle aangewys te kry is vyf persone genomineer as ouderlinge en vyf as diakens. Daarna het die Goewerneur die nominasies goedgekeur en lootjies getrek om twee ouderlinge en twee diakens aangewys te kry. Francois Retief en Carel van der Merwe is op dié wyse tot ouderlinge verkies en Christiaan Liebenberg en Roedolf Dreyer as diakens.

Op 10 Desember 1837 word die eerste amptelike kerkraadsvergadering van die Voortrekkerkerk gehou. Op versoek van die kerkraad het Retief, in sy amp as Goewerneur, die vergadering as kommissaris-politiek bygewoon. Op hierdie vergadering word onder andere besluit dat 'n maandelikse kerkraadsvergadering elke eerste Sondag van die maand gehou sal word, en dat die Voortrekkers die Kaapse kerkwet van 1824, vir sover dit toepaslik is, as kerklike wet sal aanvaar (Storm 1984: $63 \mathrm{vv}$ ).

'n Interessante en baie belangrike saak wat na vore tree, is dat die Voortrekkers hulle kerk onafhanklik en selfstandig inrig - gegrond op die Voortrekkerideaal van ' $n$ vrye kerk in die onafhanklike 'maatschappij' - los van die Kaapse Kerk wat onder Britse gesag staan. Dat die Voortrekkers hulle vertrek uit die Kolonie nie beskou het as 'n kerklike skeuring nie, spreek eintlik vanself want hulle het voortdurend getrag om predikante uit die Kaapse Kerk te verkry en so implisiet gestel dat hulle van mening was dat hulle kerk dieselfde geloofs- en belydenisinhoud het, hoewel dit 'n eie organisatoriese struktuur, los van die Kaapse Kerk, gehad het. Ook die byvoegsel tot die amps-eed van die goewerneur dui daarop dat die Voortrekkers nie 'n ander geloofsinhoud 
vir hulle kerk wou hê as dié van die kerk waarvan hulle in die kolonie lidmate was nie. Die wyse waarop hulle hulle kerk organiseer, laat egter geen twyfel dat hulle hulself as 'n onafhanklike en selfstandige Kerk, wat organies uit die Kaapse Kerk gekom het, beskou het nie. Of dit 'n oorspronklike gedagte van die Voortrekkers was om ook op kerklike gebied organisatories-onafhanklik te wou wees, is baie moeilik om te bepaal. Die negatiewe en onsimpatieke houding van die Kaapse Kerk het beslis ' $n$ rol in díe verband gespeel. Aan die ander kant is dit waarskynlik dat Piet Retief die belangrikheid ingesien het van ' $n$ 'onafhanklike' kerk om só heeltemal die Kaaps-Britse invloed en gesag te probeer ontkom; veral as ons daarop let hoe baie moeite Retief doen om Smit 'vasgestel' te kry en die kerk in te rig. Daarby moet ' $n$ mens onthou dat die verbondenheid van die kerk en owerheid by die Trekkers enigsins vanselfsprekend was omdat dieselfde mense wat die owerheid gevorm het, ook die kerk was - vir sover mens in hierdie omstandighede van 'die Kerk' kon praat. Terselfdertyd was dit volkome in lyn met die organisatoriese verbondenheid van kerk en owerheid waaraan hulle gewoond was vanaf die vroegste tye.

Hier kan dus nie sprake wees van 'n skeuring nie want 'n skeuring of afskeiding impliseer altyd 'n leerverskil. Hier was nooit 'n leerverskil aan die orde nie, maar slegs die skepping van 'n organisatories-selfstandige kerklike struktuur. Dit was ook noodsaaklik want die Voortrekkers kon, in die lig van die bepalings van die Kaapse kerkwet, artikels 9 en 10 wat verwys na die 'Hervormde Kerk in deze volksplanting' én die Herderlijke Brief van 1837 soos ook uitgevoer deur die Ring van Graaff-Reinet, nié meer lidmate van die Kaapse Kerk wees nie. In die skepping van 'n selfstandige kerklike organisasie reël die Voortrekkers die verhouding tussen"die kerk en die owerheid soos hulle dit verstaan. Oorheersend in hierdie reëling is dat die owerheid gesien word as beskermer en onderhouer van die kerk.

Piet Retief stel na sy verkiesing tot goewerneur, Erasmus Smit as herder en leraar van die Voortrekkers aan terwyl Smit nooit lidmaat of predikant van die Kaapse Kerk was of kon gewees het nie. Ook dien Retief, uit hoofde van sy amp as goewerneur, as kommissaris-politiek op die kerkraad. Smit self lê die eed van getrouheid af aan Retief, die goewerneur en staatshoof van die Voortrekkers. Smit kon verder op gesag van die goewerneur huwelike voltrek. Uit hierdie enkele sake blyk dit duidelik dat die kerkinrigting op hierdie stadium geen organisatoriese band met die Kaapse Singde gehad het nie.

'n Tweede belangrike saak wat na vore tree, is dat die Voortrekkers 
in belangrike opsigte ' $n$ ander verhouding tussen owerheid en kerk huldig en in praktyk bring as die verhouding wat in die Kaapkolonie bestaan het. In die Kolonie was die amptelike verhouding tusen owerheid en kerk nog gereël deur De Mist se ordonnansie wat onder andere vasgelê het dat geen uitsluitlike burgerlike regte of voorregte aan 'n bepaalde geloofsbelydenis verbind word nie. Verder het dit bepaal dat geen kerk bo ' $n$ ander kerk bevoordeel sou wees nie. Die implikasie van die aanvullende eed wat Retief aflê, bring egter mee dat by die Voortrekkers die teenoorgestelde gebeur. Die owerheid is, om dit so te stel, gesien as die politieke verskyningsvorm, en die kerk as die godsdienstige verskyningsvorm van dieselfde volk. Aan die owerheid word verder ' $n$ oorhoofse gesag toegeken wat beteken dat die owerheid bepaalde opdragte ten opsigte van die kerklik-godsdienstige lewensterrein moes nakom. In dié lig gesien was dit vanselfsprekend dat daar 'n onafhanklike kerk in die onafhanklike 'Voortrekkermaatschappij' moes wees. Daarom is dit ook vanselfsprekend dat die Regeringshoof amptelik beloof het om hierdie kerk organisatories en inhoudelik te beskerm en te bevorder en onder andere toe te sien dat slegs lidmate van die kerk in die Voortrekkersamelewing openbare betrekkings beklee. Erasmus Smit het hierdie verbintenis tussen owerheid en kerk geregverdig op grond daarvan dat al die Voortrekkers lidmate van dieselfde kerk was. Hierdie noue samegaan van kerk en owerheid was ook nie so vreemd nie. In 1560 verklaar die Raad van Tweehonderd van Genéve in die kerkorde van Genéve, Artikel 168: (Pont 1981: 45)

Want alhoewel die owerheid en die regeergesag wat God aan ons gegee het, en die geestelike regering wat Hy in Sy kerk verorden het, by mekaar hoort en sake is wat nie van mekaar geskei kan word nie, is hulle tog nie met mekaar vermeng nie. Hy wat alle gesag het en aan wie ons, vanweë ons pligsgevoel ons moet onderwerp, het die twee sake van mekaar onderskei.

Die interessante is verder dat hoewel die Voortrekkers die Kaapse Kerkwet van 1824 , vir sover toepaslik, as kerklike orde aanvaar het, daar géén sprake was van 'n kerklike organisasie verder as op gemeentelike en kerkraadvlak nie. Dit was in 1837 by die Blesbergvergadering ook nie wenslik nie, want die Groot Trek het nog aan die begin gestaan van die soektog na die eie vaderland. Tog is dit opvallend dat vir dié Voortrekkers gemeente en kerk dieselfde is. Vorentoe sou méér gemeentes organies voortvloei uit die één gemeente wat nou in die lewe geroep is. Die 1837-vergadering, die verkiesing van 'n eie kerkraad, die 
ordening en bevestiging van Erasmus Smit as predikant, die reëling van die verhouding met die Trek-owerheid dui alles net op een saak: die ordening van 'n eie organisatoriese selfstandige Voortrekkerkerk.

\section{DIE KERK IN NATAL, DIE VRYSTAAT EN UITBREIDING NA TRANSVAAL}

Terwyl Retief sy mense die Drakensberg af, Natal in, gelei het, het Hendrik Potgieter die Matabelevolk onder Silkaats verslaan en Transvaal en die Noord Vrystaat vir bewoning deur die Voortrekkers beveilig. Retief het egter met sy besoek aan Dingaan vir hom en sy volgelinge 'n toesegging van grond van Dingaan gekry onder sekere voorwaardes. Dit is bekend hoe Retief op 6 Februarie 1838 in Dingaan se hoofstad vermoor is en hoe daarop die moorde op die Voortrekkers by Bloukrans en Boesmansrivier gevolg het. Na die moord op Retief wou Uys Dingaan gaan straf en Potgieter se hulp is ingeroep. Die drama van Italeni is bekend. Potgieter, nooit besonder geheg aan Natal nie, het, noudat verwytend die vinger na hom gewys is as verantwoordelik vir Uys se dood en die neerlaag by Italeni, weer koersgevat na die hoogland wes van die Drakensberg. Kort voor die slag van Bloedrivier is Potchefstroom deur hom aangelê. Dié gemeenskap is deur die raad, die Raad van Potgieter, bestuur. Weens 'n gebrek aan voldoende gegewens is daar van die werksaamheid van hierdie raad so goed as niks bekend nie.

$\mathrm{Na}$ Retief se dood moes daar in Natal nuwe bestuursreëlings getref word. Dit gebeur tussen 17 Februarie en 28 Maart 1838 as 'n 'Volksraad' bestaande uit 24 lede tot stand kom wat amptelik bekend staan as die 'Raad van Representaten van het volk'. Ook is 'n grondwet opgestel wat 'Regulatien en Instructien, voor de Raad van representaten van het volk, aan Port Natal en omliggend land' genoem is. JN Boshoff, wat voorheen vrederegter en eerste klerk van die Siviele Kommissaris op Graaff Reinet was, het waarskynlik 'n belangrike rol gespeel in die opstel van die stuk. Dit was teen 4 Junie 1838 gereed. Hierdie 'Regulatien en Instructien' het met betrekking tot die kerk twee belangrike artikels gehad, naamlik artikels 13 en 15. Dit het gelui:

De Raad zal ook 'n wakend oog over die Godsdiens en Scholen moeten houden, en alles aanwenden tot bevordering der zelve; en

De Raad zal ook vlytig moeten nakomen dat in deze Maatschappy 
de Hollandse Gereformeerde Kerk ten alle tyde geprotekteerd zal worden, en erkend blijven van de hoofdkerk derzelven.

Volgens PS de Jongh het die inhoud van hierdie twee artikels daarop neergekom dat die band tussen kerk en owerheid in die Voortrekkerstraat eerder versterk as verswak is. (De Jongh 1977: 156). Heeltemal tereg ook want hier is meer uitdruklik as tevore op skrif gestel dat die owerheid ' $n$ wakende oog oor die godsdiens sou hou en alles sou aanwend om dit te bevorder. Ook sou die 'Hollandsche Gereformeerde Kerk' te alle tye deur die Volksraad beskerm word en hoofkerk bly.

Die Voortrekkerkerk het aanvanklik geen meerdere vergadering naas die Kerkraadsvergadering in hulle kerklike struktuur gehad nie. Die feit is dat die trekgroepe 'gemeentes op reis' was na hulle eindbestemming in Natal, Vrystaat en Transvaal, waar hulle eers later, na behoorlike vestiging in en bewoning van die gebied, aandag aan die skepping van meerdere vergaderings sou kon gee.

Dit het egter nie meegebring dat kerklike aangeleenthede wat deur meerdere vergaderings behartig moet word, negeer is nie. In hierdie stadium is dit egter nie die kerk nie, maar wel die Volksraad wat die leiding neem en die verantwoordelikheid aanvaar om die kerk in sy wordingsjare ' $n$ vaste fondament te gee en by te staan in breë kerklike aangeleenthede. Dit is belangrik om daarop te let dat die Volksraad hom feitlik die bevoegdhede van 'n sinodale vergadering toeëien. Waarskynlik het die Volksraad hom in hierdie praktyk laat lei deur die Kaapse voorbeeld, waaraan die Voortrekkers buitendien gewoond was. Daarby was dit so dat die lidmate van die kerk en die burgers van die Staat vir alle praktiese redes dieselfde mense was. Daarby kom dat die Voortrekkers, soos ook in 1837 geblyk het, van hulle owerheid verwag het om die kerk te beskerm en te bevorder.

So moes Piet Retief in sy ampseed op grond van artikel 36 van die Nederlandse Geloofsbelydenis belowe dat hy die kerk sal 'protekteerd en bevorderen'. Dieselfde word voorgeskryf aan die Volksraad in die 'Regulatien en Instructien' van 1838. Dit was dus vanselfsprekend dat die nuutverkose Volksraad in Natal aandag sou gee aan die kerklike en godsdienstige belange van die Voortrekkers.

Die eerste saak waaraan die Volksraad aandag gegee het was om weer na die posisie van Erasmus Smit as predikant te kyk. Sommige mense het nog steeds Smit se aanstelling as Voortrekkerpredikant bevraagteken en het geweier om sy dienste by te woon of dat hy hulle kinders doop. Die Volksraad het begin om sy aanstellingsbrief as pre- 
dikant van die 'Gereformeerde en reizende gemeente voor Natal' aan te vra. Nadat Smit dit aan hulle getoon het, het die Volksraad sy aanstelling bekragtig en ook besluit dat alle huwelike voortaan deur die predikant bevestig moes word.

Nadat Erasmus Smit op Pietermaritzburg aangekom het, het hy sy predikantswerk voortgesit. Hy het daagliks in die laer godsdienstige byeenkomste gehou en elke Sondag twee maal gepreek. Soos tevore het hy kategese-onderrig gegee, sakramente bedien en huwelike voltrek. By spesiale geleenthede het hy ook dienste gehou. Op versoek van die Volksraad het hy ook vir die uittrekkende kommando's afskeidsdienste gehou.

Die Volksraad het aan die landdros van Pietermaritzburg opdrag gegee om as kommissaris-politiek alle kerkraadsvergaderings by te woon en om ' $n$ wakende oog oor die kerk se finansies te hou. Landdros Zietsman het op 28 Januarie 1840 die kerkraadsvergadering bygewoon waartydens die volgende kerkraadslede met sy goedkeuring verkies is: $T$ Steenkamp en R Dreyer as ouderlinge en AA Smit, J van Vuuren, $S$ van Rooyen en $\mathrm{H}$ van den Berg as diakens.

Soos tydens die Trek het Erasmus Smit ook op Pietermaritzburg teenkanting in dienswerk ondervind. Hy was op hierdie staduim reeds 62 jaar oud en nog siekliker as tevore. Namate die mense meer verspreid begin woon het, het dit vir Smit al moeiliker geword om sy pligte as predikant na te kom. Die latente ontevredenheid wat daar altyd by 'n deel van die Voortrekkers was oor Erasmus Smit se aanstelling en dienswerk, het in Natal skerper na vore gekom, ook vanweë Smit se onvermoë om sy dienswerk tot bevrediging van almal te doen. Smit se teenstanders wou 'n behgorlik-opgeleide predikant beroep om die Voortrekkerkerk te bedien. Daarom het die volksraad nou geoordeel dat 'n ander leraar nodig was. Gevolglik het hulle ' $n$ 'memorie' aan 'n viertal predikante, naamlik A Faure, $T$ Herold, $G$ van der Lingen en $P$ Faure gerig waarin die predikante gevra word om namens die 'Representanten van den Trekraad' 'n predikant vir die Voortrekkers te beroep.

Ds Abraham Faure het namens die bogenoemde predikante geantwoord. Hy het gemeld dat hulle 'om zeer vele redenen bedroefd' was oor die feit dat die Voortrekkers die Kolonie verlaat het, maar hulle was tog verheug om te verneem dat hulle hul godsdienssin behou het en kerkvas was, reeds begin het om 'n kerk te bou en van voorneme was om ' $n$ 'leraar onzer Gereformeerde Kerk te willen beroepen'. Rondom die beroep was daar egter ook 'Swarigheden' en daarom moes hy eers 
antwoorde kry op die volgende vrae: Hoeveel lidmate is daar wat in die Kaapkolonie aangeneem is en wat aan die gemeente Pietermaritzburg behoort? Hoeveel persone is daar wat nog nie aangeneem is nie, maar begerig is om lidmaat te word? Hoeveel ongedoopte kinders is daar? Hoe groot is die sieletal van die gemeente? Wat sal met ds Smit gebeur as 'n Kaapse predikant die beroep aanvaar? Wat sal die traktement wees en hoe sal dit uitbetaal word?

$\mathrm{Na}$ aanleiding van hierdie skrywe van ds A Faure, waaruit die Voortrekkers afgelei het dat die viertal Kaapse predikante nie ywerig was om vir hulle 'n predikant te probeer vind nie, het die Volksraad op voorstel van Sarel Cilliers op 3 Januarie 1840 besluit om die Amerikaanse sendeling, Daniël Lindley, 'als predikant onder ons aan te stellen' op voorwaarde dat hy voor die volgende Volksraadvergadering sy dokumente toon en 'dat hy onze grondstelling van de gerevormeerde kerk aanneemt'. Op dieselfde dag is ds Lindley voorwaardelik as predikant aangestel en het die Volksraad direk daarna op voorstel van raadslid $\mathrm{KP}$ Landman 'uit naam van de gemeente' Johs Am Landman sr en Ands Pets de Jager sr as ouderling en Fredk Johs de Jager sr, Johan Hk Bredenbag sr, Lewies Forie en Evert Potgieter as diakens aangestel.

Erasmus Smit was egter nog die amptelike leraar van die Voortrekkers. Lindley se voorwaardelike aanstelling was 'voor de geene die hem verkiest'. Die verstandhouding was dat hy as predikant sou arbei totdat die Trekkers 'n predikant vir die 'Reformed Dutch Church' uit die Kaapkolonie sou kry. Op 7 Maart 1840 het die Volksraad daarom vir ds PK Albertyn, wat kort tevore sy studie in Nederland voltooi het, beroep.

Nadat ds Albertyn uiteindelik, na ongeveer ses maande se getalm, die beroep bedank het en Erasmus Smit al hoe minder aanvaarbaar geword het vir die Trekkergemeenskap, het die Volksraad vir Lindley gevra om as vaste leraar ' $n$ beroep na al die Voortrekkers aan te neem. Nadat hy sy ordeningsdokumente voorgelê het, is hy op 16 Januarie 1841 amptelik aangestel. Terselfdertyd is ds Smit beveel om sy ordeningsdokumente aan die Volksraad te oorhandig. Dit kon hy nie doen nie omdat hierdie dokumente, volgens hom, tydens die Trek soek geraak het. Daarop het die Volksraad besluit dat hy eers die dokumente aan hulle moes voorlê voordat hy weer die sakramente sou mag bedien omdat dit andersins tot onenigheid in die kerk sou lei.

Prinsipieel tree die Volksraad hier verkeerd op want dit was immers die Volksraad wat, alhoewel hulle bewus was van die wyse waarop Smit georden is, nogtans sy ordening en bevestiging bekragtig het op 
15 September 1838. As ons in ag neem dat die ontevredenheid met Smit toegeneem het en dat Lindley nou as predikant beskikbaar was, wil dit al lyk of die Volksraad van Smit as predikant ontslae wou raak.

Op 9 Februarie 1841 is ds Lindley formeel as die leraar van die Voortrekkergemeentes aangestel. Dié aanstelling sou op 1 April 1841 van $\mathrm{krag}$ word want van daardie datum af word hy vergoed vir sy werksaamhede. Hy het dadelik die aanstelling aanvaar, hoewel hy eers in Junie 1842 die 'American Board of Commissioners for Foreign Missions' se toestemming ontvang het. Op 9 Februarie is ook besluit dat Smit sy emeritaat moet aanvaar. As pensioengeld sou hy 600 riksdaalders per jaar ontvang vir die res van sy lewe. Hy sou nog in sy huis mog preek vir diegene wat na hom wou luister, maar hy mag nie sakramente bedien nie. Dit is opvallend dat die Volksraad vir Smit feitlik afsit want as emeritus sou hy tog naas preekbevoegdheid ook die reg om sakramente te bedien, moes gehad het. Dit is duidelik dat die Volksraad hier 'n patronaatsreg, op die voetspoor van die 1824 Kerkwet en die Kaapse gebruike, soos die Goewerneur in die Kaapse Kerk uitoefen. 'n Verdere opvallende en belangrike saak is dat die Volksraad in al sy bogenoemde werksaamhede nie die Kaapse Sinode of een van sy kommissies raadpleeg in enige kerklike aangeleentheid nie. Dat die Volksraad hier volkome onafhanklik van die Kaapse Kerk optree, bewys dat daar by hulle geen twyfel bestaan het dat hulle ' $n$ onafhanklike owerheid was wat ten opsigte van 'n onafhanklike kerk opgetree het nie.

Die Voortrekkergemeenskap waarvoor Lindley nou as predikant verantwoordelik was, was geweldig uitgebrei. Oos van die Drakensberge het dit die hele Republiek yan Natalia tussen die Tugela en Umzimvuburiviere ingesluit. Wes van die Berg het dit die hele PotchefstroomWinburggebied noord van die Vetrivier beslaan; 'n gebied waar tussen $8000-12000$ (Lindley het dit op 20000 geskat) mense woonagtig ws.

In die organiese totstandkoming van die kerk in díe gebied sou hy 'n belangrike rol speel. Dit is egter foutief om te beweer dat daar eers met Lindley se aanstelling begin is met die organisasie van die kerk onder die Voortrekkers. Vanaf 1837 was daar onder die Voortrekkers 'n gemeentelike organisasie met ouderlinge en diakens sowel as 'n predikant in funksie. Die Volksraad van Natal, die Potgieter-Raad, sowel as die Adjunkraad van Potchefstroom het voor Lindley ook reeds vir die godsdienstige belange van die Trekkers gesorg. Behalwe vir die aanstelling van kerkraadslede het die Volksraad in Natal reeds in 1839 besluit om 'n kerkgebou op te rig ter nakoming van hulle gelofte. Nog 
voor die vereniging van die Potgieter-Raad met die Natalse Volskraad het laasgenoemde Dawid Francois Jacobs as ouderling en katkisasiemeester vir die gebied wes van die Drakensberge aangestel. Hy het toe waarskynlik in die Winburgse wêreld gewoon. Op 1 November 1841 is uit Potchefstroom 'n kollektelys uitgestuur om 'n kerk op Potchefstroom gebou te kry. Dit word gerig aan: (TA SSI R 88/41).

Waarde Broeders Landgenoten en mede Lee(de)maten der Hervormde Kerken, beneven alle Christelijken Kerken van Zuid-Afrika.

Hierdie lys is onderteken deur krygsoffisiere, landdros en heemrade en deur PJ van Staden as kerkraad. Oor die aanstelling van laasgenoemde is daar geen gegewens bekend nie. Ons moet aanneem dat hy deur die Raad van Potgieter aangestel is om die geestelike versorging van Potchefstroom-mense waar te neem.

Ds Lindley is op 25 Januarie 1841 amptelik in kennis gestel van sy aanstelling. Spoedig daarna het hy te Pietermaritzburg die kerkraadslede, wat op 18 Januarie deur die Volksraad aangestel is, in hulle onderskeie ampte bevestig. Alhoewel hy op Pietermaritzburg gewoon het, het Lindley ook Weenen, Port Natal en die Winburg-Potchefstroom gebied bearbei. Hy het na homself verwys as die 'emigrants pastor' en van sy arbeidsveld gesê:

My gemeente het die hele gebied van Natal, die Oranje Vrystaat en Transvaal beslaan. Ek het verskillende lang reise na die binneland onderneem en het vir sommige van my gemeentelede eredienste gehou tot aan die 25 ste graad suiderbreedte. Ek was die enigste predikant vir die hele uitgestrekte gebied wat ek genoem het en ek dink ek was verantwoordelik vir die geestelike versorging van nie minder nie as twintigduisend lidmate.

Op 25 en 26 Maart 1842 het Lindley sy eerste besoek aan Potchefstroom gebring. Tydens dié geleentheid is die kerkraadslede wat op 18 Januarie 1842 deur die Volksraad aangestel is, bevestig. Ook is nagmaal en doop bedien, geleentheid is gegee vir die aflegging van geloofsbelydenis terwyl Lindley ook ' $n$ lidmaatregister aangelê het.

Lindley sou die Transvaal weer'n keer in Mei en Junie 1844 besoek. Tydens die geleentheid sou hy so ver gaan as die Magaliesberge en moontlik ook die oostelike buitewyke van Marico besoek. Die pleknaam 'Lindleyspoort', enkele myle noordoos van Swartruggens, herinner ons waarskynlik aan sy besoek van 1844 . 
Ook vir die kerk in die Vrystaat was Lindley van besondere betekenis. Op 31 Maart 1842 het hy te 'Wenburg' (Winburg) die eerste doopen lidmaatregister aangelê. Ooreenkomstig die doopregister moes Lindley op sy drie besoeke aan die gebied in 1842, 1844 en 1845, 1303 kinders gedoop het. Verder het hy 583 lidmate belydenis van geloof laat aflê en 97 pare in die huwelik bevestig.

Teen die einde van 1842 het die Voortrekkerkerk bestaan uit die vyf gemeentes, naamlik: Port Natal, Pietermaritzburg, Weenen, Winburg en Potchefstroom met ds D Lindley as enigste predikant, wat gewoon het op Pietermaritzburg vanwaar hy die hele gebied bearbei het. Die vroegste gegewens waaroor ons beskik dateer uit 1843 en deel ons die volgende mee: (A Dreyer 1929: $69 \mathrm{vv}$ ).

Dat de Volksraad, uit hoofde van de uitgestrektheid des lands, waarover de Emigranten verspreid waren, de bevolking in vijf gemeenten heeft verdeeld; zijnde drie ten oosten, één ten westen, en ééne ten noorden van den Draakberg. In elke gemeenten zijn kerkeraden aangesteld en bevestigd. $\mathrm{Zij}$ hebben onder zich slechts eenen leeraar, den Wel-Eerw. Heer Daniël Lindley, die zijn verblyf heeft te Pietermaritzburg, de eenige plaats alwaar als nog een kerkgebouw is gesticht, en die, nu en dan, de overige gemeenten bezoekt.

\section{[1] De gemeente Natal (Durban)}

Ouderlingen in dezelve waren: A De Jager; en S Landman; en Diakenen: L Fourie en Fr. de Jager. Negen en sewentig kinderen hadden en, sedert de oprigting der gemeente, den doop ontvangen. Sterkspruit maakt de grensscheiding uit tussen de parochie van Natal en Pietermaritzburg.

\section{[2] De gemeente Pietermaritzburg}

De Kerkraad van deze gemeente bestaat uit den Wel. Eerw. Daniël Lindley, - de Ouderlingen: Th. Steenkamp, CA Cilliers, EF Potgieter, Bernard S Rudolph; en de Diakenen: GR van Rooyen, $P$ Pretorius, Mz., JH Bruwer, H Lemmer, G Naude, J Boshoff. Aldaar werden en gedoopt in het jaar 1841: 284 kinderen; in 1842: 244 kinderen; en in 1843: 148 kinderen ... De grensscheiding tussen de parochie van deze plaats en Weenen, is Mooye Rivier.

[3] De gemeente Weenen

Weenen, 138 mijlen van Nátal gelegen.... Alhier zijn Ouderlin- 
gen: P Cronje en Abr. Spies; en Diakenen: NJ Smit, F Joubert en Jan Davel. In die gemeente zijn een honderd kinderen gedoopt. 378 mijlen van Natal en 150 van Colesberg, is Winburg.

\section{[4] De gemeente Winburg}

Een zeer uitebreide parochie, zich uitstrekkende van de Vet Rivier tot Rhenoster Rivier. Ouderlingen zijn er: M Smit; en Diakennen: Fr. Biljoen, J van der Westhuizen. In deze gemeente doopte de Wel. Eerw. Heer Lindley, gedurende zijn bezoek in 1842, 362 kinderen. 460 mijlen van Natal ligt Potchefspruit.

[5] De gemeente van Potchefstroom

Deze gemeente neemt in bevolking sterk toe. Vele menschen wonen ruim 532 mijlen afstands van Natal en 660 van Colesberg. Ouderlingen: F Wolmarans, $P$ van Staden; Diakenen: P Strydom, P du Preez, Step. Viljoen en Jacob Maree. 202 kinderen ontvingen in deze gemeente den doop, in een bezoekreis van den Wel. Eerw. Lindley in 1842.

Teen die einde van 1842 is die hele gebied deur die Volksraad dus in vyf gemeentes verdeel naamlik Pietermaritzburg, waar Lindley gewoon het, Port Natal, Weenen, Winburg en Potchefstroom. Met sy besoekreise en sy hardwerkendheid het Lindley die fondamente van die kerklike organisasie in die Voortrekkerrepubliek stewig gelê en het hy toegesien dat die kerklike organisasie gedra is deur bekwame kerkraadslede. Lindley se dienswerk was vir die Voortrekkerkerk van geweldige waarde in dié tyd toe die Kaapse Kerk skerp negatief en afwysend teen die Voortrekkers gestaan het.

Dit moet beklemtoon word dat die Voortrekkerkerk in hierdie tyd organisatories volkome onafhanklik van die Kaapse Kerk was. Lindley was self nooit 'n lidmaat van die Kaapse Kerk nie en is, net soos Erasmus Smit, deur die Volksraad, sonder medewerking van die Kaapse Kerk as predikant aangestel. Die lidmate en kerkraadslede was ook nie meer lidmate van gemeentes van die Kaapse Kerk nie, maar was ingeskakel in die gemeentes van die Voortrekkerkerk. Juis deur in elke gemeente 'n lidmaatregister aan te lê, het Lindley sorg gedra dat die selfstandige bestaan van elke gemeente binne die geheel van die kerk op 'n vaste grondslag geplaas word. Uit die aard van die saak is nog nie aan ' $n$ meerdere vergadering gedink nie want voorlopig het die Volksraad nog daardie funksie vervul. Terwyl die Volksraad getrag het om die onafhanklikheid van die Voortrekkerrepubliek deur Engeland er- 
ken te kry, het die Voortrekkerkerk sy onafhanklikheid uitgeleef (Pont 87: 185).

\section{ONDERWERPING AAN BRITSE GESAG}

Ofskoon die Britse regering, hoofsaaklik vanweë finansiële oorwegings, nie begerig was om Natal kort na die Groot Trek te annekseer nie, was hulle egter ook nie bereid om die onafhanklikheid van die Voortrekkers te erken nie. Vandaar dat 'n reeks herhaalde versoeke deur die Natalse Volksraad om amptelike erkenning en samewerking deur Sir George Napier, die Britse goewerneur aan die Kaap, afgewys is. Aan hierdie onbesliste beleid kom daar op 2 Desember 1841 ' $n$ einde as Napier per proklamasie verklaar dat die Trekkers in Natal, Britse onderdane was en nie die reg het om op onafhanklikheid aanspraak te maak nie, dat hulle nie die reg daartoe sal kry nie en dat hy met 'n militêre besetting van Port Natal gaan herbeset (Muller 1968: 145).

$\mathrm{Na}$ aanvanklike hardnekkige weerstand het die Volksraad van Natal op 15 Julie 1842 aan Britse gesag oorgegee.

Die Britse anneksasie sou nie net op politieke gebied nie, maar ook op kerklike gebied, gevolge vir die Voortrekkerkerk meebring. Die grootskaalse verhuising van lidmate as gevolg van die Britse anneksasie na die gebiede van Transvaal en die Vrystaat, het die gevolg gehad dat die gemeentes Weenen en Port Natal tot niet gegaan het, sodat teen 1847 slegs die gemeente Pietermaritzburg oorgebly het. (Van der Watt 1977: 43). Weenen sou in 1859 weer herstig word en Port Natal eers in 1914. In die geval van die gemeente Pietermaritzburg, het die Kaapse goewerneur onmiddellik sy gesag laat geld en die ius patronatus wat hy in die Kaapse Kerk uitgeroep het, net so in Natal gaan uitoefen. Ons kan beweer dat die Britse goewerneur, nadat Natal in Mei 1844 finaal as 'n distrik van die Kaapkolonie geproklameer is, nie alleen politiesstaatkundige beheer oor Natal aangeneem het nie, maar gesien die noue verbondenheid van die kerk aan die Kaap, die Natalse gemeente as 't ware vir die Kaapse Kerk geannekseer het. So word ds Lindley op 6 Februarie 1846 as predikant van Pietermaritzburg heraangestel sonder dat hy ooit deur die Kaapse kerklike liggame as predikant toegelaat is. Reeds in 1844 word die Kaapse kerkwet van 1842 geldend vir Natal en word so finaal die band met die Voortrekkerkerk afgesny.

Winburg-gemeente sou dieselfde paadjie loop. Saam met die politieke anneksasie van die Transgariep het ook die oorname van dié Voortrekkergemeente gegaan. Dit is opvallend dat dit elke keer die 
Britse goewerneur is wat die gemeentes by die Kaapse kerklike struktuur ingeskakel het. Die lidmate of die bestaande kerkvergaderings is nooit geraadpleeg nie. So het sir Harry Smith, die goewerneur van die Kaap, op 14 Maart 1849 die Natalse en Transgariepse gemeentes formeel ingelyf by die Kaapse kerklike struktuur en word dié gemeentes ook deel van die Ring van Transgariep wat in 1850 deur die Sinodale Kommissie van die Kaapse Kerk in die lewe geroep word (Die Gereformeerde Kerkbode 45: 314).

Teen 1850 het van die oorspronklike Voortrekkerkerk nog net Transvaal as 'n onafhanklike gebied oorgebly. Net so het van die onafhanklike Voortrekkerkerk nog net die Transvaalse gemeentes oorgebly.

Die Natalse en Vrystaatse gemeentes is deur die Britse Goewerneur van die Kaapkolonie sonder enige vorm van raadpleging van die lidmate, by die Kaapse Kerk gevoeg. Die Ring van Transgariep was die Kaapse Kerk se manier om die gemeentes wat as gevolg van die Britse imperialistiese optrede in sy skoot geval het, kerklik in te skakel en deel van die Kaapse kerklike struktuur te maak.

\section{Literatuurverwysings}

DIE GEREFORMEERDE KERKBODE, Deel II nr 45.

DE JONGH, PS 19774. Die lewe van Erasmus Smit, Pretoria.

DREYER, A 1929. Die Kaapse Kerk en die Groot Trek. Kaapstad.

MULLER, CF] 1968. 500 jaar Suid-Afrikaanse geskiedenis. Pretoria.

PONT, AD 1981. Die historiese agtergronde van ons kerklike reg. Pretoria.

PONT, AD 1987. Die Voortrekkerkerk 1836-1852. Kerkregaantekeninge, B D III, Universiteit van Pretoria.

STORM, JMG 1984. Die Voortrekkerkerk: 'n Historiese kerkregtelike studie van die Nederduitsch Hervormde Kerk 1836-1853. D D proefskrif, Universiteit van Pretoria.

Transvaalse Argief. SSI.

VAN DER WALT, PB 1977. Die Nederduitse Gereformeerde Kerk 1834-1866, Deel II, Pretoria.

VAN JAARSVELD, FA 1974. Geskiedkundige verkenninge. Pretoria. 